\title{
Design criteria for flood-defense structures based on probabilistic cost- benefit optimization with value at risk (VaR) methods. Application to the Choluteca River in Tegucigalpa (Honduras)
}

\author{
Eduardo García Alonso ${ }^{1, a}$, Jorge Rojo Gómez ${ }^{1}$, César Álvarez Díaz ${ }^{1}$, Pedro Díaz Simal ${ }^{1}$ and Roberto Mínguez Solana ${ }^{2}$ \\ ${ }^{1}$ Environmental Hydraulics Institute "IH Cantabria". Parque Científico y Tecnológico de Cantabria, C/ Isabel Torres, 15, 39011 Santander, \\ Cantabria. Spain \\ ${ }^{2}$ Independent consultant. C/ Honduras 1, 13160 Torralba de Calatrava, Ciudad Real, Spain
}

\begin{abstract}
A probabilistic CBA framework, combined with a Value at risk (VaR) methods, as applied in financial risk management, can be used to select the best mitigation scheme among several alternatives and reliability levels, based on a quantitative and objective procedure. The proposed method looks for the alternative that minimizes the accumulated maximum damage that can be produce by any particular sequence of events, over the life span of the structure, using numerical simulation and possibly including interactions among individual events (two large floods within a short time cannot damage twice the same assets). This is equivalent to a stochastic optimization problem, where the entity to be minimized are the maximum losses. The optimal alternative, based on a VaR criteria (including conditional $\mathrm{VaR}$ ), differs largely from the one that maximizes the average NPV, and is more stable, compared with the average or a deterministic NPV. To demonstrate the proposed procedure, and show the differences among the three performance indicators (average NPV, VaR and CVaR), the case of the Choluteca River in Tegucigalpa, capital city of Honduras, are used, with real data of economic and human damages provided by a recent study by IDB.
\end{abstract}

\section{Motivation}

Extreme floods are ubiquitous and represent the most common natural catastrophes around the world [1]. In comparison with other hazards as earthquakes and landslides, floods are expected to increase in magnitude and frequency in many regions of the world, due to climate change and land-use transformation processes. The global investment needs in flood reduction schemes for the next decade are expected to be huge, and many of them will be aimed at developing Countries, where the financial conditions do not bode well for large public infrastructures. The problem of money allocation for flood reduction schemes will come more and more to the forefront, as the human and economic damages due to extreme events become more frequent and harsher, and their impacts become more global. In any case, there will probably be a need to increase and polish the ex-ante project evaluation and appraisal techniques for flood reductions programs, in order to optimize the allocation of economic resources, in a context of over-demand for this type of interventions.

There is a growing trend to analyze flood reduction schemes from the point of view of cost-benefit analysis (CBA), including as an income the spared losses and

\footnotetext{
${ }^{a}$ Corresponding author: edelwar@gmail.com
}

possibly other monetized public benefits as land value surpluses and indirect damage reduction (traffic interruptions, commercial activity, etc.). Many financial institutions, and in particular development banks as WB, IDB and ADB advocate for cost-benefit analyses of public infrastructures, including risk reduction schemes, in order to guarantee a coherence between the resourced needed and the resulting benefits; furthermore, CBA is a convenient tool to benchmark different alternatives, even different in nature, for a particular problem, and eventually select the fittest one.

This paper stems from the authors' experience in the application of CBA to the evaluation of flood reduction schemes in several countries (mainly of middle and low income) over the last decade, and tries to reflect on some of the strengths and weaknesses of such approach for this particular type of projects. Although CBA is a simple and powerful tool, it has some limitations, when applied to evaluate and design flood mitigation alternatives for a particular site. Firstly, there is an inherent difficulty in dealing with human damages. The human dimension of flood risks is usually characterized in terms of affected population (with several possible definitions), refugees (people in need of shelter due to the destruction of their houses), number of casualties, deceased, etc. CBA has to 
express such losses in monetary terms, which opens a moral dilemma and leaves the choices of unit prices to the subjectivity of the practitioner. This issue will not be the main concern of this work, although some comments and suggestions will be given on how to address it.

A second drawback of the CBA approach is the stochastic nature of the natural phenomena triggering the flood risks: rainfall, discharges, storm surge and other sources are random processes, sometimes with complex cross-correlations, that should not be treated in a deterministic way. Since the timeline of damages is dictated by the stochastic sequence of extreme events, and the reduction or mitigation of such damages is the final goal of any intervention, ACB should implement the probabilistic nature of the hazards. Furthermore, ACB is based on the economic quantification of the value of time through a compound-interest discount rate, which makes more compelling the need to pay attention to the chronological structure of extreme events. In a standard CBA, both investments and revenues are treated in a deterministic way, and spared costs are introduced as a mean annualized damage, often obtained from the distribution of damages for selected events. This approach dodges the probabilistic nature of extreme phenomena and their highly variable patterns of occurrence in time. Since ACB is based on the timevarying cost of money through an interest rate, the exact sequence of events that a particular investment will withstand largely affects its financial profitability, measured as its net present value (NPV), which shows high volatility, depending on each realization of the series of floods, possibly fitted with a certain extreme value distribution.

Finally, there are other potential limitations of the CBA approach for flood mitigation appraisal, which will not be here addressed:

- Extrapolation of stationary risk conditions for several future decades is usually not possible, at least without a high degree of uncertainty, due to the complex co-evolution of socioeconomic processes and risk-generating mechanisms.

- Compound-interest discount rates are the pillar of CBA, financial analysis and capitalism in general, but after consistently applying it in natural risk analysis, there is a pervasive feeling that they fail to properly balance the short and the long term. This is particularly noticeable when benefits, particularly social or environmental, are expected after several decades, when typical discount rates make them vanish. Other discount expressions with a less abrupt asymptotic behaviour are available, but at the cost of a blurred economic significance.

This paper puts forward a methodology, based on Monte Carlo simulation of different realizations of sequences of extreme events, to perform a probabilistic CBA to evaluate and benchmark flood mitigation projects. It draws on several concepts and tools that have been used in the financial realm since the 1980's, but have seldom or not at all been applied for public infrastructures. Financing a mitigation scheme to reduce flood risks is itself a highly risky decision, albeit the use of public money and the difficulty in monetizing some of its benefits (human, social, environmental) make it less evident, or simply moves the decision making to the political arena. The proposed method tries to counteract these facts and give both decision-makers and politicians a more pragmatic view of the nature of the problem they face.

Currently, many of the economic appraisals of public infrastructures carried out by financing institutions around the world rely on an expert-based, scenario-driven approach, in which a particular investment generates a series of deterministic cash flows over time, which eventually can be summarized in a set of profitability parameters (net present value, internal return rate, equilibrium time, payout ratio, etc.) indicating how good the investment is. Here, it will argued that a value-at-risk (VaR) method could be more realistic and reflect in a better way the nature of the decisions under consideration, especially when assessing risk mitigation schemes. From this standpoint, the decision-maker should focus on minimizing the economic risks involved in a particular decision or, in other words, make sure that the maximum losses to be attained are minimum. In this framework, the key feature is the tail of the probability density function (PDF) of the net present value (NPV) for a particular alternative/scenario. The most effective alternative is the one that gets to push the right tail of the NPV distribution furthest towards the negative axis (reminder: losses are positives by convention), implying that the maximum failure or loss is minimum. Basically, we advocate for the use of new measure of profitability, a $\mathrm{VaR}$ or more exactly a variant of it (the conditional value at risk or $\mathrm{CVaR}$ ), instead of the classic average NPV. This new measure requires the consideration of the cash flows and their discounted sums as probabilistic functions, making the procedure somehow more datademanding and cumbersome to apply, at least with a standard spreadsheet.

\section{Methodological procedure}

\subsection{CBA fundamentals for flood reduction studies and conventions}

In this context, the following cash-flow generating items will be considered when evaluating a particular set of flood reduction alternatives: 


\begin{tabular}{|l|l|}
\hline $\begin{array}{l}\text { Adaptation and } \\
\text { mitigation costs }\end{array}$ & $\begin{array}{l}\text { Fixed infrastructure costs } \\
\text { Variable costs (infrastructure } \\
\text { maintenance and management costs) }\end{array}$ \\
\hline $\begin{array}{l}\text { Direct economic } \\
\text { damages }\end{array}$ & $\begin{array}{l}\text { On buildings } \\
\text { On public infrastructures }\end{array}$ \\
\hline $\begin{array}{l}\text { Direct human } \\
\text { damages }\end{array}$ & $\begin{array}{l}\text { Affected population } \\
\text { Number of refugees } \\
\text { Fatalities }\end{array}$ \\
\hline $\begin{array}{l}\text { Indirect effects } \\
\text { (damages of benefits) }\end{array}$ & $\begin{array}{l}\text { Traffic } \\
\text { Loss/gain of commercial profit } \\
\text { Land value }\end{array}$ \\
\hline
\end{tabular}

As a convention and for simplicity, both the capital expenditures related with flood mitigation works (and maintenance), and the damages derived from the extreme events are equally treated as expenses, with positive sign; benefits (i.e. negative quantities under this convention) from the previous table could only be generated through indirect effects (for instance, capital gains derived from an increase of the land value). An alternative approach, assuming that the CAPEX in mitigation works is a cost and reductions of damages (with respect to the scenario without mitigation works) are a benefit, is ultimately equivalent but will not be used here. It will also be assumed that CAPEX takes place over the first five years of the simulation.

\subsection{Stochastic optimization and optimal risk}

Optimization in a classic (deterministic) framework deals with the problem of finding a particular set of parameters (real numbers or integers) that minimize/maximize an objective function, subject to some restrictions (equalities and/or inequalities) expressed as linear or non-linear algebraic expression. The discipline of solving this type of problems when the objective function (or even the constraints) involve some kind of uncertainty is called stochastic programming [2], and has become more and more popular in many areas over the last decades. Some of the most popular applications of these techniques take place at the beginning of the XXI century for stock-portfolio management [3], where the problem is to select a set of stocks (or any other financial instrument) whose valuation can withstand market shocks with minimum losses. It can be proved that this approach also provides good yields in case of a bull market (i.e the average yield is also increased when losses are minimized) but it is often more sensible to focus on the shape of the lower tail. Other applications in areas as energy markets [4], hydroelectric systems [5] and behavioural ecology [6] show the success of this approach for solving complex, real-world problems.
A simple and widely used risk measure is the Value-at-Risk at the $\alpha$ confidence level, or $\alpha$-VaR. This is a point measure that is defined as the value of the empirical distribution of the variable of interest (in this case, as will be shown, is the net present value NPV associated with a particular scenario) whose probability of exceedance is $1-\alpha$. Another measure that has recently gained popularity in practical applications is the conditional value-at-risk at the confidence level $\alpha$ or $\alpha$ $\mathrm{CVaR}$, which quantifies all the information included in the upper tail of the loss distribution (in this case the NPV), starting from a particular threshold, which is the probability of non-exceedance $\alpha$. This risk measure has some interesting mathematical properties, being coherent in the sense of Artzner et al. and preserving linear programming solvability [7]. Since CVaR considers the whole tail of the loss distribution, it also takes into account the very extreme, although very rare, events that may happen, and therefore the overall shape of such tail. For practical purposes, $\alpha-\mathrm{CVaR}$ in the context of this paper can be obtained by sorting in descending order all the data sampled from the theoretical distribution of losses, and averaging the highest $(1-\alpha) \%$. For instance, if 1000 simulations of the losses are performed and $\alpha=0.95$, the $\mathrm{CVaR}$ would be the average of the highest 50 values.

\subsection{Sources of uncertainty and scenario generation}

In this work, alternatives to mitigate flood risks are embedded into the wider concept of scenario, which is defined as the combination of three components:

A. A statistical characterization of the future extreme climate, focusing on the hazard/s (rainfall, river discharge, sea level, etc.) that induce the damages. One or more coupled climatic sources can be considered, based on an annual maxima, exceedance over threshold, continuous simulation, etc.

B. A particular risk mitigation scheme, with its associated costs. Such scheme can possibly entail a set of coordinated actions of different nature, structural and non-structural.

C. A set of relationships between the hazard/s (measured as the intensity of the representative variable, ie rainfall, discharge, sea level, etc) and the expected damage, in one or several dimensions (economic, human, environmental, etc), for that particular mitigation scheme.

The first component is strictly stochastic in nature, while the second and the third can be dealt with either in a deterministic or probabilistic way. In this paper, we will focus on the uncertainty associated with the climatic forcing, while the investment costs and damages (components $\mathrm{B}$ and $\mathrm{C}$ of a scenario) will be considered as 
deterministic. However, the proposed method is equally suitable to address the uncertainty in the estimates of the capital expenditure and damages (which imply the effectiveness of the proposed measures). The uncertainty associated with the hazard-risk relationships (component C) is particularly important, since it encompasses the evolution of socioeconomic and urban development factors, which are highly complex and unpredictable (e.g.; the damages caused by a particular storm at present in a particular site can be estimated with certain accuracy, while the damages in 2050 will be highly dependent on how the land uses or city fabric evolve).

As in standard CBA, the proposed method can then be used to several purposes:

- Benchmark alternatives of very different nature (e.g. coastal retreat vs. sand nourishment vs. seawall).

- Obtain the design level for a particular type of alternative (e.g. select the optimal return period for which a river encroachment should be designed).

- Apply optimization on any set of decision variables, possibly within a broader simulation software.

The practical case included in this paper exemplifies the second of the aforementioned applications.

\subsection{General description of the model and basic hypotheses.}

Based on Monte Carlo simulation, many realizations of a particular scenario must be generated, and eventually obtain the cumulative distribution of the net present value (NPV), from which the average NPV, $\mathrm{VaR}$ and $\mathrm{CVaR}$ can be obtained. All fluxes are simulated at a yearly time step, although lower time increments could be used if needed. The procedure requires two additional financial parameters, which are common to all scenarios under consideration: the temporal discount rate (r) applied to the cash flows and the confidence level $(\alpha)$ used for $\mathrm{VaR}$ and $\mathrm{CVaR}$. The number of realizations needed to obtain a valid estimate of such statistics must be empirically established on a case-by-case basis (see application case in section 3 )

For a particular scenario, adaptation and mitigations costs (component B) usually come first in time, with a high initial capital expenditure (civil works, land retreat with resettlement, etc.), followed by periodic maintenance and/or upgrade costs. These costs are the same in every realization, showing no dependence on each particular sequence of disasters (a certain dependence could be assumed between disasters and repair/maintenance costs, but is not considered here for the sake of simplicity).

On the other hand, damages are directly linked to each particular sequence of extreme events triggering them. In the basic version of the model, the following simplifying assumptions will be adopted, in order to make the results easier to interpret:

- Flood defences remain in place and fully functional over the total time span. Annual maintenance costs are assumed to be $1 \%$ of the total initial investment.

- The reconstruction of damaged assets is full achieved within the same year when they are produced. This implies that the system has no memory, and that the same assets can be deteriorated as many times as needed during a simulation.

- Human damages are not converted into economic figures and do not affect the CBA. It would be straight forward to assume a unit price for every affected person, refugee or casualty.

- Capital gains due to an increase in the land value due to flood protection are not considered

After exploring this basic version of the model, a variant of it will be introduced, to take into account that the effects of several events can overlap. To this purpose, a reconstruction rate will be introduced, which will be dependent on the number of affected people and their average economic recovery power (RP), measured in $\$$ per person and year. This guarantees that an asset cannot be damaged twice, unless it has been fully restored to its initial value, which will only happen if there has been enough time for recovery.

Capital gains due to land appreciation could be introduced as a potential benefit of implementing a flood alleviation scheme, but it requires data on the area of urban land which is protected and the surplus that is induced by such protection. The fist data is readily available from hydraulic modelling, but the latter is much more difficult to ascertain. Furthermore, in case of an event exceeding the design level of the encroachment, the land will flood again and the land surplus will be erased, although in a deferred way and increasing to a certain extent the NPV of the alternative. This effect will not be considered in the current version of the model. 


\section{Test case: the Choluteca River in Tegucigalpa (Honduras)}

\subsection{General context of flood risk analysis in Tegucigalpa}

The capital City of Honduras, Tegucigalpa, is one of the largest cities in Central America with around 780,000 people, and belongs to the Emerging and Sustainable Cities Initiative (ESCI) promoted by the Inter-American Development Bank (IDB). Among other basic studies, a comprehensive flood risk analysis has been recently carried out in its metropolitan area [8], with special focus on the central district, called "the Almond" (Figure 1) which is crossed by the Choluteca River. Several outbursts of this river over the last decades have caused severe damages in the surrounding areas, with Hurricane Mitch in 1998 standing out as one the most harmful natural disasters ever experienced in this region.

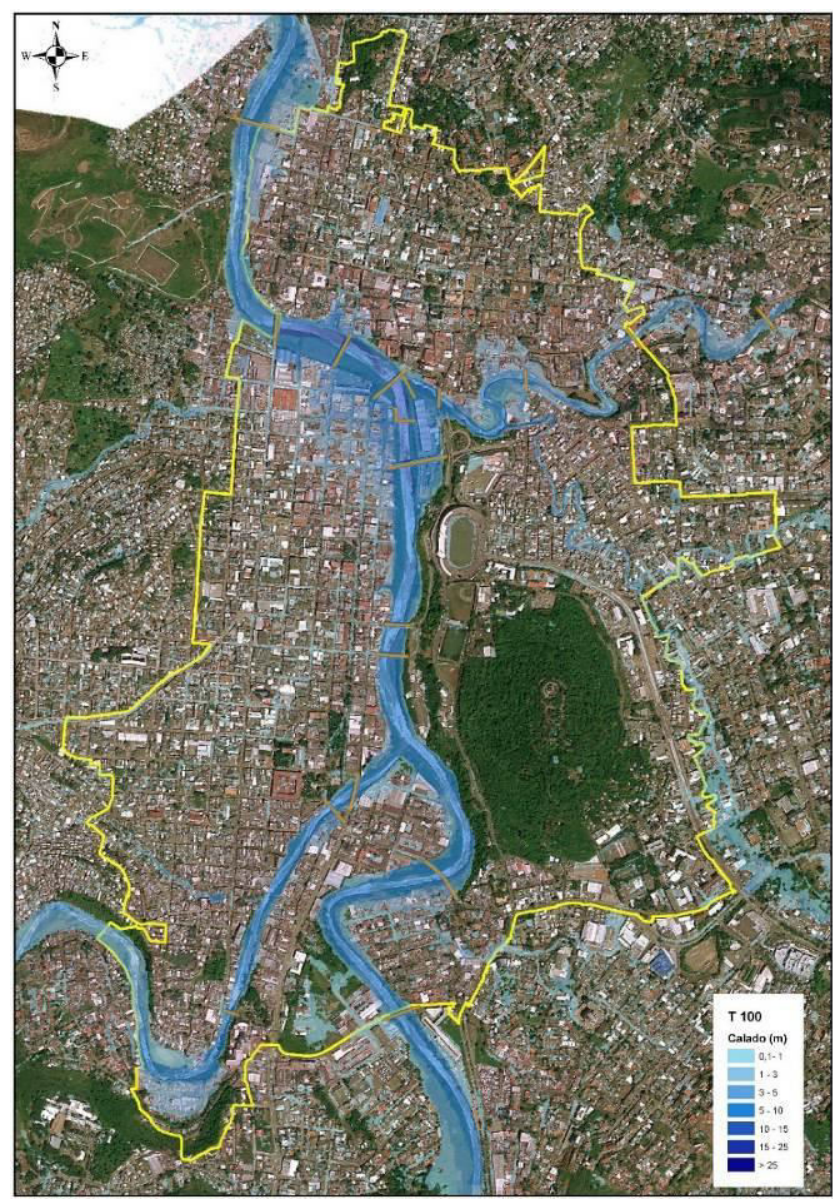

Figure 1. Detail study area and water depths for a 100-year flood in the present situation. Source: IDB [8].

Flood risk studies following IDB standards include an evaluation of the hazards on a detailed DTM with a 2D hydraulic model (InfoWorks ICM, by Innovyze), a characterization of exposure and vulnerability features of the study area and, finally, a spatial representation of the risks in two distinct dimensions: human (affected people, refugees and potential human losses) and economic (direct damages on buildings and damages on critical infrastructures). This results are obtained for events associated with several return periods $(10,20,50,100$ and 500 years), and for at least three scenarios: the urban layout at present and two projection of the urban sprawl for 2050, assuming different (optimistic vs. pessimistic) development pathways.

The "smart" scenario for 2050 assumes that a set of measures to mitigate risks will be implemented, and in the case of Tegucigalpa, one of the most important measures is an encroachment of the Choluteca River along approximately $2.8 \mathrm{~km}$, as it crosses the city center (Figure 2); a tentative cross section of the intended encroachment is also shown in Figure 3. As a financial institution, IDB demands a cost-benefit analysis (CBA) of any potential public infrastructure, and in this case a classic/deterministic CBA was performed, based on the average annual economic losses, estimated from the results of the available events. Indirect losses due to traffic disturbances and loss of commercial profit in two large public markets were also considered. Assuming a $12 \%$ discount rate, as is customary in the Bank for this type of investment, and considering a 50-year return period as the design level for the levees and associated infrastructures, the investment was deemed profitable.



Figure 2. Perspective on the intervention zone (red lines) for which the proposed model will be tested. Water depths correspond to the 100-year flood event. Source: IDB [8]. 


\subsection{Input data and assumptions for the probabilistic CBA}

The information available in the aforementioned risk study will be now used to exemplify the methodology preented in this paper to perform a probabilistic costbenefit analysis. The main purpose is to determine the appropriate design level for a river encroachment in the centre of Tegucigalpa, so that the minimum achievable NPV of the investment is maximized (i.e. the financial risk is minimized).

Three statistics of the NPV distribution will be used as potential decision parameters: mean value, $\alpha-\mathrm{VaR}$ and $\alpha-\mathrm{CVaR}$; the value of $\alpha$ used for all simulations was 0.95 . The series of maximum annual daily rainfall in the river basin have been fitted with a Generalized Extreme Value distribution, based on the available data, with parameters $\{\mu, \sigma, \mathrm{k}\}=\{14.7,53.9,0.049\}$. Table 1 summarizes the risks obtained for particular extreme events, obtained by combining 2D hydraulic results with a spatial classification of building typology and population density; a zoom of the risk results obtained at a particular hot spot in the city centre is presented in Figure 4 . The selected damage functions are the ones provided by CAPRA [9] and linear interpolation has been used to interpolate risks in-between the available return periods. Indirect damages due to traffic disturbances and commercial losses were obtained from available monographies provided by IDB (see full references in [8]).



Figure 3. Sketch of the proposed average cross section for the river training in Tegucigalpa. Source: IDB [8].

The CAPEX of the encroachment works for the different design levels have been estimated using local prices for macro-units from similar works. The higher the design return period, the wider and deeper the required bankfull section. Since in the original risk study only the current situation (without encroachment) and the proposed works designed to withstand a 50-year flood were analysed, it has been assumed for all the design levels that the same law of damage vs. excess over the design threshold applies; the estimated daily rainfall threshold for river overflow is $72.8 \mathrm{~mm}$, without any flood reduction scheme. For instance, a $150 \mathrm{~mm}$ flood with an encroachment designed with reliability of 20-year (equivalent to $101 \mathrm{~mm}$ of rainfall, see table 1) causes the same damage as a storm of $121.8 \mathrm{~mm}(72.8+150-101)$ without training works. It is preferable, but time consuming, to calculate specific damages for each alternative (in this case each design level) and for all return periods above the design threshold; in this particular case, this information was not available.

\begin{tabular}{|l|c|c|c|c|c|}
\hline \multicolumn{1}{|c|}{ Tr (years) } & $\mathbf{1 0}$ & $\mathbf{2 0}$ & $\mathbf{5 0}$ & $\mathbf{1 0 0}$ & $\mathbf{5 0 0}$ \\
\hline $\begin{array}{l}\text { Rainfall } \\
\text { (mm/d) }\end{array}$ & 88.9 & 101.0 & 117.2 & 129.9 & 160.9 \\
\hline $\begin{array}{l}\text { Mitigation } \\
\text { costs (M\$) }\end{array}$ & 10.0 & 15.0 & 22.5 & 30.0 & 57.5 \\
\hline $\begin{array}{l}\text { Affected area } \\
\text { (ha) }\end{array}$ & 46.6 & 51.3 & 57.0 & 63.9 & 77.5 \\
\hline $\begin{array}{l}\text { Direct Econ. } \\
\text { damage (M\$) }\end{array}$ & 23.2 & 27.1 & 32.5 & 45.5 & 65.9 \\
\hline $\begin{array}{l}\text { Ind. econ. } \\
\text { damage (M\$) }\end{array}$ & 1.8 & 1.8 & 1.8 & 1.8 & 1.8 \\
\hline $\begin{array}{l}\text { Affected } \\
\text { people }\end{array}$ & 7040 & 7633 & 8360 & 9065 & 10794 \\
\hline Deceased & 1.1 & 1.4 & 1.8 & 2.7 & 4.2 \\
\hline Refugees & 297 & 367 & 463 & 676 & 1068 \\
\hline
\end{tabular}

Table 1. Basic data for Tegus CBA. Some of them are not used in the current version of the CBA model, but are shown for information purposes. Source: IDB [8] with minor changes.

The number of realizations for each case was 10000 , after checking that a convergence of the results, for practical purposes, was achieved. The length of the simulated yearly series has been made dependent on the discount rate, and are usually between 200 and 1000 years, for large and small discount rates, respectively. Matlab was used to run the model and process the results.

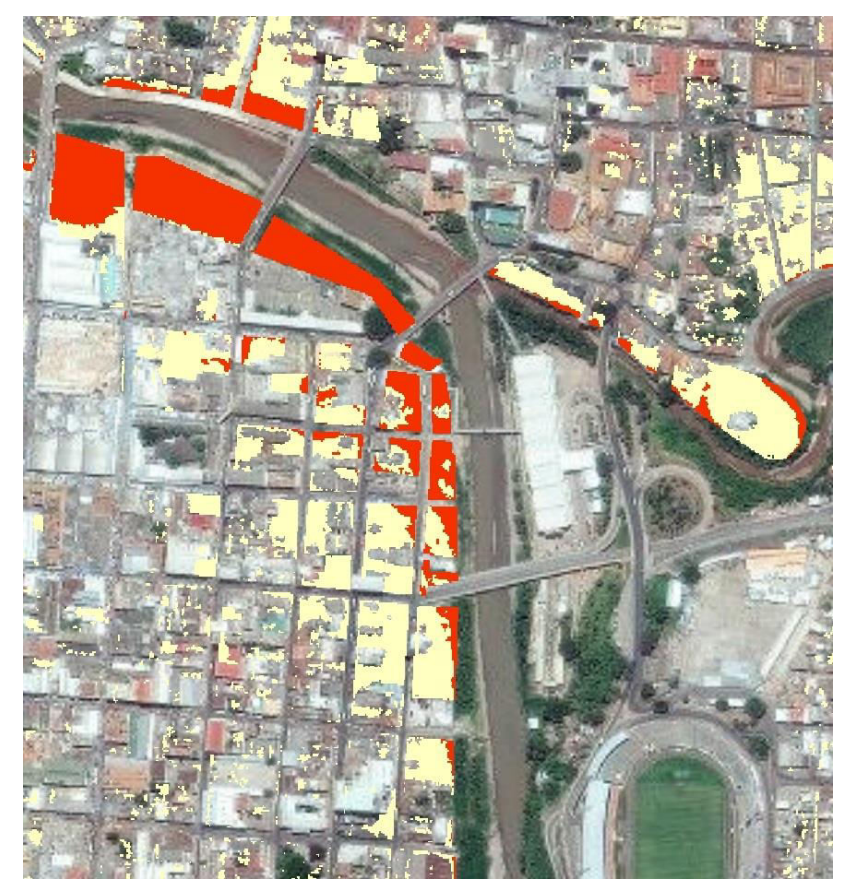

Figure 4. Detail of the map of economic risks for the present situation in a 100-year flood. This information, at an aggregated level, has been used for the CBA as presented in Table 1 . Source: IDB [8]. 


\subsection{Results}

After running the model in its basic version, the key results are shown in Figures 5 and 6. Figure 5 shows the variation of the three efficiency parameters with the design level, using a fixed discount rate of $8 \%$. The best alternative is the one that minimizes the risk parameter in the $\mathrm{Y}$-axis, and according to this, it is clear that the average NPV produces a clearly distinct minimum, which is less pronounced with the $\mathrm{VaR}$ and $\mathrm{CVaR}$ parameters. In particular, the option that maximizes average gains (or equivalently minimizes average losses) must be designed to withstand the 40-years event, while the best alternative using the other two criteria is more stringent (around 100 years).

Furthermore, the minima in the latter cases are less pronounced, implying that there is not much difference, in terms of profitability, as long as the design level lies within the interval of 60 to 150 years. In other words, the value-at-risk indicators dictate a higher design level and also make somehow irrelevant this decision, beyond a certain figure. Both the VaR and CVaR show the same behaviour and, at least for this case and discount rate, give similar results.



Figure 5. Variation of the three performance parameters with the design level, in the basic version of the model and discount rate of $8 \%$.

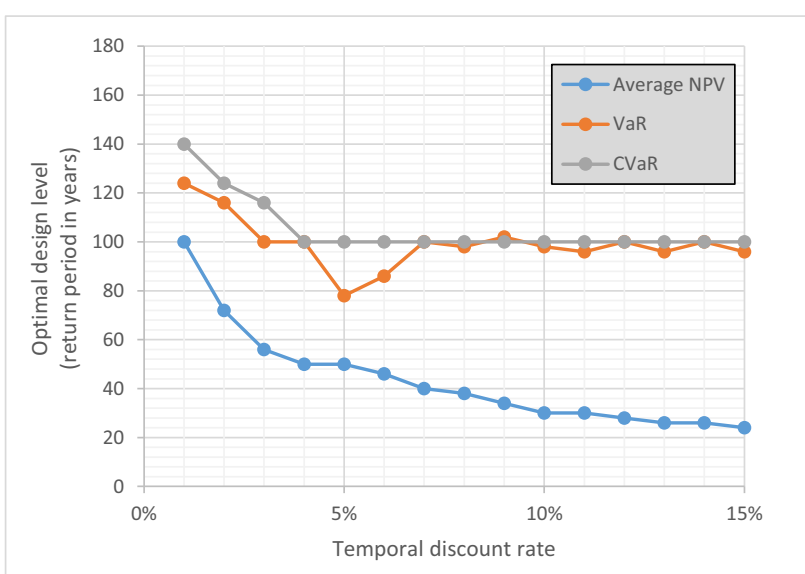

Figure 6. Optimal design levels as a function of the discount rate, for the three performance parameters.
Figure 6 shows the results of the optimal solutions, in terms of the design level, depending on the discount rate. The main conclusions are summarized as follows:

1) The criteria based on the tail of the NPV distribution (VaR and $\mathrm{CVaR}$ ) yield different results from the average NPV criterion; in particular they suggest a much higher design level.

2) The average NPV yields optimal design levels that get lower as the discount rate increases. Therefore, this criterion is sensitive to the chosen return rate. However, $\mathrm{VaR}$ and $\mathrm{CVaR}$ are affected by discount rates only if they are below $5-6 \%$; beyond such figures, the optimal design stabilizes at around 100 years.

3) Applying the model with 10000 realizations of each scenario, the results obtained using CVaR are more stable than with the standard quantile VaR. They yield, at least for this particular application, similar results, but the $\mathrm{CVaR}$ is more robust and converges faster.

It is somehow surprising that the tail-based indicators diminish the influence of the discount rate in the decision making, and also suggest that there is not a clear design optimum, at least for practical purposes, but a wider set of them. Obviously, these conclusions apply strictly for the conditions of Tegucigalpa and its specific figures, and cannot be extrapolated to other sites or conditions.

The time sequence of catastrophes and their interactions, which entail reconstruction rates, is a complex topic, and only a rough and preliminary approach is tested here. In this variation of the basic CBA model, reconstruction rates are limited by the available resources, and therefore only the assets that have been fully re-built can be re-damaged. Therefore, the sequence of extreme events reflects "potential" losses, but does not translate directly into "real" losses. Potential losses become real if there is enough money and time for the damaged assets to recover their initial value. The number of people affected by a particular event, and their average economic capacity of recovery (USD/pers·year) are the factors that yield the recovery rate; average income per person is the key parameter governing recovery rates, but also physical constraints apply (even in wealthy context, full recovery from a large flood would take 3-5 years).

Figure 7 shows how the optimal design levels vary with the unit recovery power (RP) in the case of Tegucigalpa, using a discount rate of $8 \%$. For RP above $400 \$$ pers $\cdot y e a r$, the best design level is similar the one obtained in the basic model, where RP is considered infinite. Below that figure, it happens that the total effective damage caused by a particular series of storms is lower, because the reconstruction pace does not allow full recovery of the destroyed assets. In the limit, if RP is null, the total damage is equivalent to the damage of the worst storm experienced over the total length. Due to this effect, optimal design levels considering reconstruction 
rates are lower for every performance indicator, and particularly so for $\mathrm{VaR}$ and $\mathrm{CVaR}$.



Figure 7. Optimal design levels as a function of the recovery power. Discount rate of $8 \%$.

A recovery power of $300 \$ /$ pers $y e a r$ implies that a 100 -year storm needs around 15 years for full recovery and, during such period of time, smaller storms cause a reduced damage. This could be the case in Tegucigalpa when hurricane Agatha stroke in 2010: many flooded places had already been hit by hurricane Mitch in 1998 and 12 years later were still partially reconstructed.

In Figure 8, a realization of events, without temporal discount, are presented as generated by the model $(\mathrm{RP}=300 \$$ /pers'year). It can be seen that the potential damages (positive Y-axis) do not always equal the effective damages (negative $\mathrm{Y}$-axis). The event that takes place on year 25 th would potentially cause damages up to 20 MUSD, while real damages are only 5 MUSD, due to the fact that there had not been enough time to recover from a previous event (year 18th).

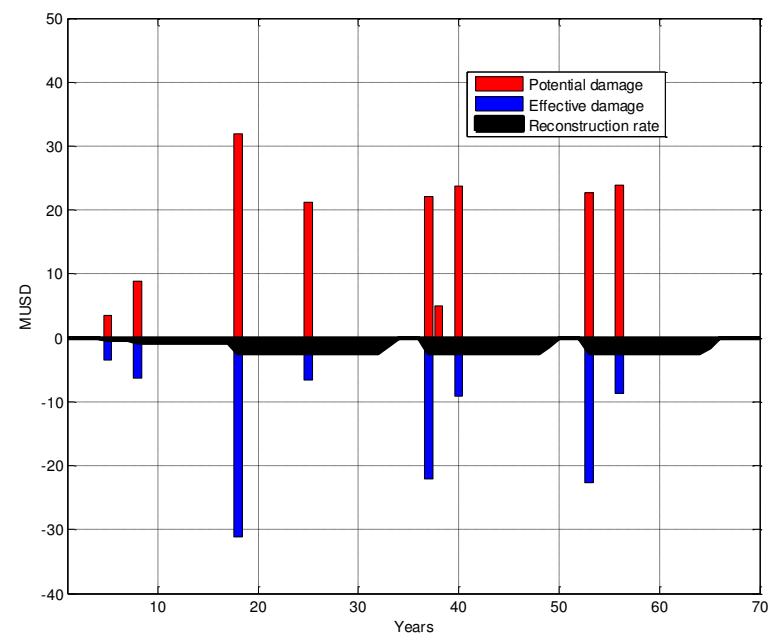

Figure 8. Non-discounted potential and effective damages from a random realization of flood events, considering a recovery power of 300 \$/pers. year. Effective damage and reconstruction CAPEX are shown in black in the negative Y-axes for clarity, but are positive values.

\section{Summary and conclusions}

The benchmarking of different alternatives to solve a particular problem based on econometrics and costbenefit analysis, is a widespread activity and usually sheds some light on the most convenient option; CBA, usually combined with other heuristic or expert-based methods (multi-criteria, Delphi methods, etc), provide altogether a quite comprehensive toolbox to enrich public debate and help decision-makers justify their decisions.

This paper underscores the fact that the mitigation of natural risks, and in particular the design of flood defense structures, poses a particular challenge, since the benefits they provide (basically the reduction of human and economic losses) are strictly linked to the sequence of natural phenomena causing the damages (usually extreme rainfalls and sea-levels), and these are essentially stochastic. On this basis, a probabilistic approach to CBA is endorsed, as the standard (deterministic) procedure based on an average annual damage (pure premium) does not provide any insight on the variability of the effectiveness of a flood reduction scheme. In other words, the risk involved in the decision on which is the most suitable scheme to alleviate floods at a particular site, is at least as high (although of a very different nature) as the risk of getting wet, and has till now received little attention.

Once within a probabilistic framework for CBA, the classic NPV becomes a statistical variable with an empirical cumulative distribution. In this work, it is suggested that the best performance indicators, at least in some sense, are the ones that minimize the maximum losses (and the variance of them altogether), instead of the average value of the distribution. This value-at-risk approach is here addressed via two indicators: the straight-forward $\mathrm{VaR}$, which is a particular $(\alpha)$ quantile of the NPV distribution, and the conditional version of it or $\mathrm{CVaR}$, which is an average of all values included in the tail of the empirical NPV distribution, above a certain threshold.

The application case of the encroachment of the Choluteca River in Tegucigalpa (Honduras) is used to test the proposed approach. Most of the inputs for the model are obtained from a comprehensive risk study of the central part of the city by IDB. Firstly, a basic application of the model is used, in which recovery from any particular event is immediate. The average NPV criterion yields a lower optimal design level which is highly dependent on the discount rate. The VaR and CVaR parameters yield higher return periods, and the result is less sensitive to the discount rate; the latter is more stable (i.e. converges faster), but there seems to be little difference between both, at least for this case.

A variant of the model, including the overlapping effect between events has also been tested, assuming that the power of recovery is proportional to the number of affected people and to an average available income of the population. For low recovery rates, the optimal solution tends to be different, with lower design levels, than for the basic case. 
There is a logical propensity in most financing institutions to present flood mitigation schemes to potential borrowers as totally safe and usually profitable investments. In reality, flood works are designed to withstand extremely uncertain loads, both in intensity and time of occurrence. Some of the main sources of profitability for flood protection structures are usually difficult to estimate: land value surpluses and reduction of indirect costs (i.e. traffic and commercial activity, as in Tegus); in developed countries, high-value properties and activities can easily justify any investment in mitigation measures (London, New York, etc.). This paper puts forward a probabilistic approach to CBA that can be applied to this type of projects at a scoping phase, to preselect among several alternatives. Value-at-risk methods should be considered as performance indicators, once the probabilistic approach has been embraced.

In the example of Tegucigalpa, only the uncertainty in the climatic forcing has been considered, but all types of uncertainties affecting the rest of variables can be added to the same framework. It is suggested that a probabilistic CBA with $\mathrm{VaR}$ indicators gives more insight into the real nature of a flood mitigation problem, and may usher in a richer and more fruitful debate among stakeholders, in order to find the most suitable solution for each particular case.

\section{Acknowledgements}

The authors would like to thank the staff of IDB, and in particular Mr. Ginés Suárez and Mr. Horacio Terraza, for their comments and the information provided, and the staff of the consulting company IDOM S.A for the fruitful collaboration.

\section{References}

1. WWAP (United Nations World Water Assessment Programme). 2015. The United Nations World Water Development Report 2015: Water for a Sustainable World. Paris, UNESCO.

2. Ruszczyński, Andrzej; Shapiro, Alexander (2003).Stochastic Programming. Handbooks in Operations Research and Management Science 10. Philadelphia: Elsevier. p. 700.ISBN 9780444508546.

3. Rockafellar RT, Uryasev S (2000) Optimization of conditional value-at risk. J Risk 2(3):21-41

4. Conejo AJ, García-Bertrand R, Carrión M, Caballero A, de Andrés A (2008) Optimal involvement in futures markets of a power producer. IEEE Trans Power Syst 23(2):703-711

5. N. Löhndorf, D. Wozabal, S. Minner, Optimizing trading decisions for hydro storage systems using approximate dual dynamic programming, Operations Research \#61 (2013) pp. 810-823.

6. Mangel, M. \& Clark, C. W. 1988. Dynamic modeling in behavioral ecology. Princeton University Press ISBN 0-691-08506-4
7. Artzner, P., Delbaen, F., Eber, J. M., \& Heath, D. (1999). Coherent measures of risk. Mathematical finance, 9(3), 203-228.

8. Banco Interamericano De Desarrollo. Estudios base para Tegucigalpa, Honduras. Componente 2 - Riesgo de desastres y vulnerabilidad ante el cambio climático. Parte A. Estudio probabilístico de riesgos por inundaciones. Informe final. Versión 9.10.2015.

9. Cardona, O. D., Ordaz Schroder, M. G., Reinoso, E., Yamín, L., \& Barbat Barbat, H. A. (2010). Comprehensive approach for probabilistic risk assessment (CAPRA): international initiative for disaster risk management effectiveness. InInternational Symposium on Reliability Engineering and Risk Management (pp. 1-10). 